\title{
Comparison of technological efficiency of gravitational devices for preparation of large diluted coal
}

\author{
Vladimir Udovitsky ${ }^{1, *}$, Vladimir Kandinsky $^{1}$ and Artyom Begunov ${ }^{1}$ \\ ${ }^{1}$ T.F. Gorbachev Kuzbass State Technical University, Department of mineral resources processing, \\ 650000 Kemerovo, 28 Vesennya st., Russian Federation
}

\begin{abstract}
The purpose of the work is to assess the possibility of preparation of poor washability, high-ash coals demonstrated by the example of the Apsat deposit. The following tasks have been accomplished. The analysis of modern equipment produced for washing of large classes of coal: heavy-medium separators and jigging machines. The most preferred were the heavy-media separator SKVP, jigging machines ROMJIG and BATAC. The analysis of mathematical models of processes and technologies of gravitational processing for determining the yield and ash content of the concentrate has been carried out. Algorithms and computer programs have been developed in which two mathematical models of the processes of heavy-media preparation and jigging machines have been used that allow determination of the separation densities at which the maximum yield of the total concentrate of the required ash content is reached. The computational experiment carried out showed that in processing of high ash diluted coals with poor washability, it is expedient to use SKVP separator and a jigging machine ROMJIG.
\end{abstract}

\section{Introduction}

Recently, more and more attention has been paid to the processes and technologies of coal preparation. Such technologies belong to the priority direction "Rational Nature Management" and allow a more complete extraction of the combustible mass from run-ofmine coal. Coal plays a significant role in the energy balance of Russia and especially Siberia [1]. In developing deposits, diluted rock mass is formed, which due to high ash content cannot be sold. It is only possible to increase its commodity value, especially for large classes, after its preparation.

\section{Materials and Methods}

Beneficiation of large classes of energy coals, as a rule, is carried out in one stage with the separation of two products: concentrate and rock. The density of separation depends on the

\footnotetext{
*Corresponding author: uvi@kuzstu.ru
} 
fractional composition of coal, the quality requirements of the products obtained and is taken equal to 1.65 to $2.05 \mathrm{~g} / \mathrm{cm}^{3}$.

To implement this scheme, heavy-media wheel separators SKVP [2], drum separators WEMCO [3] and jigging machines BATAC and ROMJIG are used to process large coals [4-6].

Since 1975 Teska type heavy-media wheel separators SVKP have found the greatest distribution in Russia in preparation of coals, anthracites and shales with lump size of 13 (25) to $300 \mathrm{~mm}$ due to reliability and high efficiency of separation. The designs of separators and technical characteristics are presented in sufficient detail in the reference literature [2].

In 1985 the jigging machine ROMJIG by MBE was successfully tested in difficult conditions during continuous operation at the Emil Mayrisch mine in Germany. The machine was used to separate rocks from anthracite. The size of the processed material was 30 to $400 \mathrm{~mm}$.

In the jigging machine ROMJIG, the unloading of rock and concentrate is carried out by a twin elevator wheel (Fig. 1).

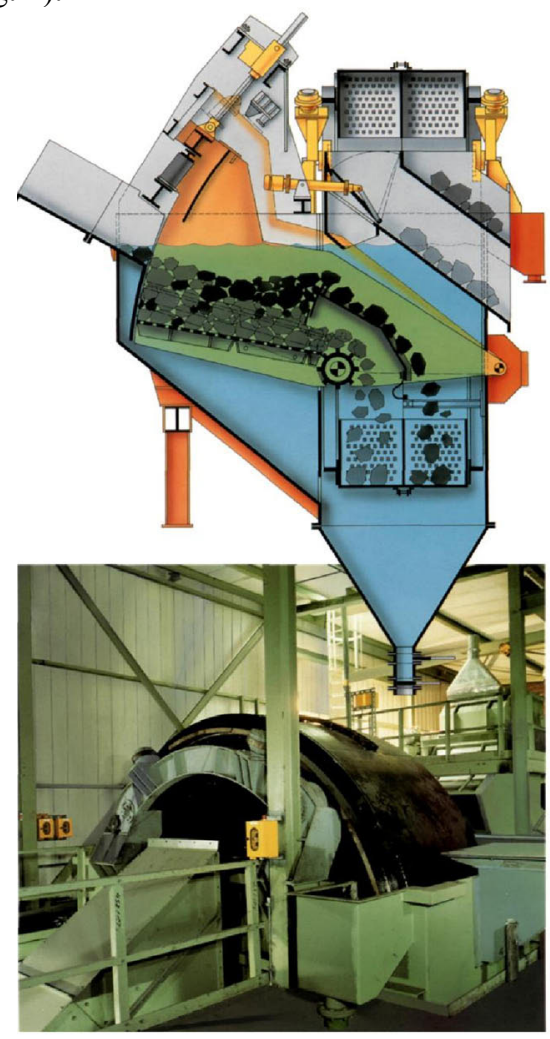

Fig. 1. Jigging machine ROMJIG with a twin elevator wheel

The jigging process in this machine takes place in an water medium. Bed loosening required for preparation is implemented by lifting with the help of hydraulics and the subsequent sharp lowering of the swinging jigging sieve with the material on it. The draw of the rock is performed by a special unloader, which simultaneously restrains the flow of material. To regulate the thickness of the bed on the sieve during its rise in the hydraulic system, the pressure is measured, which is used as an input parameter in the unloader rotation speed control system. 
When the concentrate and rock are unloaded by the elevator wheel, there is also a partial dewatering of the material. The fines falling through the holes in the wheel get into the conical part of the machine and are transported through the sluice device for sorting by the size.

At the quarry in Binet (India), the following technology is used to wash coal with an ash content of $41 \div 45 \%$. ROM coal is crushed to a particle size of less than $400 \mathrm{~mm}$ and is classified on a screen with a sieve hole size of $30 \mathrm{~mm}$. Dry screening (less than $30 \mathrm{~mm}$ ) is combined further with the product released from the machine through the sluice device and dehydrated on the screen. A large class of $30-400 \mathrm{~mm}$ is processed on three jigging machines ROMJIG [5, 6].

The concentrate with a density of less than $1.9 \mathrm{~g} / \mathrm{cm} 3$ with an ash content of $30-31 \%$ is combined with ROM coal to produce a product with $34 \%$ ash content and shipped to a power plant.

For underground operations, a ROMJIG machine with a small constructional height has been designed. In this version, the machine is equipped with a scraper conveyor, unloading the rock, on the canvas of which the preliminary water removal takes place. The lighter material above the rock falls into the tray and is unloaded from it by a large-diameter screw conveyor. The material, which has passed under the jigging sieve, is removed by means of a screw device and lifted by a bucket elevator with simultaneous dehydration.

The BATAC jigging machine produced by MBE for preparation of coals with a particle size of $13-150 \mathrm{~mm}$ (Fig. 2) is successfully used at the Ziminka preparation plant in Prokopyevsk, Russia.

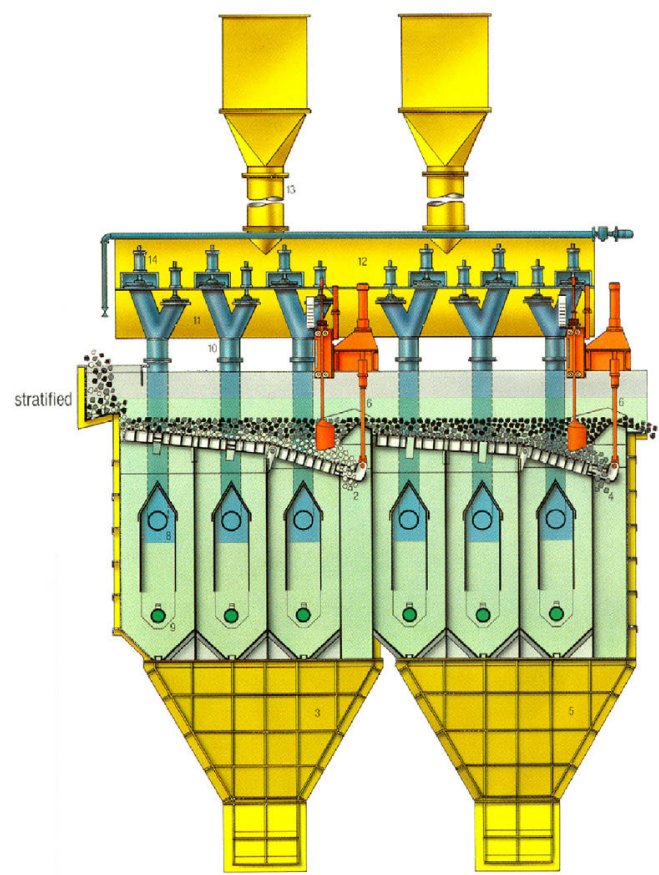

Fig. 2. The BATAC jigging machine

In its design the machine is based on air pulsation. Vibrational movement of water is set by means of air supplied to the air chambers located under the jigging sieve. Compressed air is periodically supplied to the chambers using electronically controlled pulsators, which expands to raise the water level, creating an upward flow relative to the sieve. The material on the sieve (bed) rises with the water and separates, depending on the density and size. 
Small and light particles are in the upper layers of the bed, heavy and large - in the lower layers.

Further, the air supply by the pulsators is stopped and a time of pause occurs, during which the separation of the bed ends.

Then, the rotary dampers of the pulsators (depending on the design of the machine) release air from the air chambers into the atmosphere, creating a descending flow relative to the sieve. There is a condensation and movement of the material by transport water along the inclined sieve to the discharge pouch. Small heavy particles are discharged through the holes of the jigging sieve, large ones through the pocket. The lighter particles, together with the water, move to the next jigging compartment, in which the stratification process is similar.

In addition, sub-sieve water is supplied to the bottom of each jigging compartment, which enhances the ascending and weakens the downward flow of water.

The sub-grid arrangement of the air chambers allows achieving equal rates of ascending flow over the entire area of the jigging sieve, which contributes to an increase in the efficiency of separation of mineral particles in the machine.

\subsection{Initial data}

As raw material, coal of $25-100 \mathrm{~mm}$ in size was sampled at the Apsat deposit [7], the fractional composition of which was determined by the SibNII-Coal Preparation Institute (Table 1).

Table 1. Fractional composition of coal with lump size of 25-100 mm

\begin{tabular}{|c|c|c|c|c|c|c|}
\hline $\begin{array}{c}\text { Density of } \\
\text { fractions, } \\
\text { g/cm }\end{array}$ & \multirow{2}{*}{$\begin{array}{c}\text { Yield, } \\
\text { \% }\end{array}$} & \multirow{2}{*}{$\begin{array}{c}\text { Ash } \\
\text { content, } \\
\mathbf{\%}\end{array}$} & \multicolumn{2}{|c|}{ Floaters } & \multicolumn{2}{c|}{ Sinkers } \\
\hline & & Yield, \% & Ash content, \% & Yield, \% & Ash content, \% \\
\hline$<1.3$ & 8.3 & 7.4 & 8.3 & 7.4 & 100.0 & 27.4 \\
\hline $1.3-1.4$ & 45.4 & 13.1 & 53.7 & 12.2 & 91.7 & 29.2 \\
\hline $1.4-1.5$ & 20.8 & 20.9 & 74.5 & 14.6 & 46.3 & 44.9 \\
\hline $1.5-1.6$ & 6.3 & 27.3 & 80.8 & 15.6 & 25.5 & 64.5 \\
\hline $1.6-1.8$ & 3.5 & 38.8 & 84.3 & 16.6 & 19.2 & 76.7 \\
\hline$>1.8$ & 15.7 & 85.1 & 100.0 & 27.4 & 15.7 & 85.1 \\
\hline Total & 100.0 & 27.4 & - & - & - & - \\
\hline \multicolumn{7}{|c|}{ Washability very difficult, $T=36.3 \%$} \\
\hline
\end{tabular}

\subsection{Mathematical model}

The use of a probabilistic method for the distribution of fractions of various densities into products of preparation for calculating the yields (1) and ash contents (2) of the concentrate in gravitational apparatuses first proposed by the authors of the publications [8-10] is mentioned in the work [11]:

$$
\begin{array}{r}
\gamma=\sum_{i=1}^{n} \gamma_{i} \cdot \Phi\left(x_{i}\right), \\
A^{d}=\frac{\sum_{i=1}^{n} \gamma_{i} \cdot A_{i}^{d} \cdot \Phi\left(x_{i}\right)}{\sum_{i=1}^{n} \gamma_{i} \cdot \Phi\left(x_{i}\right)},
\end{array}
$$


where $n$ - number of fractions; $\Phi\left(x_{i}\right)$ - the value of the probability integral; $\gamma_{i}, A^{d}{ }_{i}-$ yield and ash content of $i$-th fraction; $x_{i}$-deviation of average density of fractions $\rho_{l}$ from the intended separation density $\rho$.

The value $x_{i}$ for the jigging concentrate is calculated by the formula (3), for the heavymedia separator SKVP - by the formula (4):

$$
\begin{gathered}
x_{i}=\frac{0.675}{\ln \left(I^{2}+\sqrt{I^{2}+1}\right)} \cdot \ln \frac{\rho-1}{\rho_{i}-1} ; \\
x_{i}=0.675 \frac{\rho-\rho_{i}}{E_{p}} .
\end{gathered}
$$

\section{Results and Discussion}

At computer calculation $[12,13]$ of processes of gravitational coal washing, in technological schemes dilution of washing products in heavy-media separators SKVP is determined by the formula (5):

$$
E_{p m}=0.01 \rho+0.02 \text {. }
$$

The values of the error of separation (imperfection) $I$ in the formula (3) for the jigging machines ROMJIG ${ }^{\circledR}$ and BATAC ${ }^{\circledR}$ are taken according to the data of MBE, the machine manufacturer [6], and are equal, respectively: 0.11 and 0.09 .

The mathematical model and computer implementation of the probabilistic method of fractional distribution in calculating the technological scheme of coal enrichment in three machine classes in order to achieve the maximum yield of the total concentrate of the required ash content is shown in the works $[14,15]$.

The publication [16] shows the realization of the well-known theorem of Reinhardt on the achievement of a maximum yield of the total concentrate of a given ash content in the enrichment of several coals.

In mathematical models of processes of gravitational enrichment the formulas published in [14-16] were used. Table 2 shows the results of computer simulation of the processes of gravitational enrichment of coals of the Apsat deposit, the fractional composition of which is presented in Table. 1. The values of the yields and ash contents of the concentrate for heavy-media enrichment and jigging machines were calculated at separation densities varying from 1.40 to $1.80 \mathrm{~g} / \mathrm{cm}^{3}$.

Table 2. Values of concentrate yield and ash content calculated for a separator and a jig

\begin{tabular}{|c|c|c|c|c|c|c|}
\hline \multirow{2}{*}{$\begin{array}{c}\text { Separation } \\
\text { density, } \\
\text { g/cm }\end{array}$} & \multicolumn{2}{|c|}{ SKVP } & \multicolumn{2}{c|}{ BATAC } & \multicolumn{2}{c|}{ ROMJIG } \\
\cline { 2 - 7 } & Yield, \% & $\begin{array}{c}\text { Ash content, } \\
\text { \% }\end{array}$ & Yield, \% & $\begin{array}{c}\text { Ash content, } \\
\text { \% }\end{array}$ & Yield, \% & $\begin{array}{c}\text { Ash } \\
\text { content, } \\
\%\end{array}$ \\
\hline 1.40 & 49.74 & 12.67 & 50.48 & 12.78 & - & - \\
\hline 1.45 & 63.10 & 13.67 & 63.16 & 13.73 & - & - \\
\hline 1.50 & 71.97 & 14.53 & 71.37 & 14.53 & 70,85 & 14.52 \\
\hline 1.60 & 79.75 & 15.50 & 79.29 & 15.50 & 79.02 & 15.49 \\
\hline 1.70 & 82.53 & 16.12 & 82.32 & 16.09 & 82.20 & 16.08 \\
\hline 1.80 & 84.18 & 16.56 & 83.76 & 16.46 & 83.68 & 16.46 \\
\hline
\end{tabular}




\section{Conclusions}

Computational experiments established:

1. The calculated value of the concentrate yield of the SKVP separator is higher by 0.2$0.3 \%$ of the concentrate yield of the jigging machines at a separation density of $1.7 \mathrm{~g} / \mathrm{cm}^{3}$.

2. For the mechanized separation of the rock in order to reduce the ash content of steam coals of large classes, it is advisable to use SKVP or ROMJIG, since BATAC can wash coal with a particle size of less than $150 \mathrm{~mm}$.

3. It should be noted that the design features of the jigging machine ROMJIG allow to achieve: a minimum separation density of $1.5 \mathrm{~g} / \mathrm{cm}^{3}$; completeness of separation of the rock to $90 \%$ at the separation density of $1.85 \mathrm{~g} / \mathrm{cm}^{3}$; specific consumption of electricity -0.2 $\mathrm{kWh} / \mathrm{t}$; specific water consumption $-0.03 \mathrm{~m}^{3} / \mathrm{t}$.

4. Particularly it is necessary to emphasize that ROMJIG has elevator unloading of the rock, which is very important when enriching the diluted rock mass when the yield of the rock is very large.

\section{References}

1. Information on http://www.gks.ru/

2. J.W. Leonard, B.C. Hardinge, Coal Preparation (SME, Littleton, CO, 1991)

3. G.J. Sanders, D. Ziaja, J. Kottmann, Coal Prep. 22 (2002)

4. M. Wesp, H. Thelen, H. Müller, G. Wüster, Aufbereit, Tech. 30 (1989)

5. J. Winckler, G. Mustafi, in: Mining Challenges of the 21st Century (APH Publishing Corp., New Delhi, 2000)

6. K. Tromp, Neue Wege fur die Beuerteilung der Aufbereitung von Steinkohlen (Gluckauf, 1937)

7. A. Terra, Revue de lindustrue minerale (1939)

8. A. Terra. Sens de la courbe de partage anamorphosee et de lecart probable dans le controle des lavoirs (R. I. M., 1955)

9. B.S. Gottfried, Int. J. Miner. Process. 5 (1978)

10. L.H.E. Weyher, Mining Congress Journal, 7 (1971)

11. T. Gouri Charan, Coal beneficiation (CRC Press, Boca Raton, FL, 2015)

12. V. Udovitsky, XX International Mineral Processing Congress (Aachen, Germany, 1997)

13. V. Udovitsky, Regional APCOM'97 Symposium: The Moscow State Mining University (Publishing Center Moscow, Russia, 1997)

14. I. Korolev, V. Udovitsky, XVIII International Coal Preparation Congress (SaintPetersburg, Russia, 2016) 